\title{
RISCOS ERGONÔMICOS ENFRENTADOS PELO ENFERMEIRO: UMA REVISÃO NARRATIVA
}

\author{
Carine Sabin Ayres ${ }^{1}$, Deise Denise Friedrich², \\ Simone dos Santos Nunes ${ }^{3}$
}

\begin{abstract}
RESUMO: A Enfermagem é a profissão que possui mais frequência de contato com os pacientes e, por esse motivo, é classificada como a quarta profissão mais estressante no setor público. Isso acarreta em várias consequências para esses profissionais da área da saúde, inclusive, riscos ergonômicos, tais como, movimentos corporais e posturas inadequadas. Objetivo: analisar as produções científicas geradas acerca dos riscos ergonômicos enfrentados pelo enfermeiro por meio de uma revisão narrativa. Com a seguinte questão norteadora: "O que tem sido produzido cientificamente acerca dos riscos ergonômicos enfrentados pelo enfermeiro?" Método: 0 estudo consiste em uma revisão narrativa, realizada através das bases de dados: LILACS, PubMed e MEDLINE, os descritores utilizados foram: "ENFERMAGEM" [Palavras] and ("ERGONOMIA") or "RISCOS OCUPACIONAIS" [Palavras] and "SAÚDE DO TRABALHADOR" [Palavras]. Para a amostragem, foram analisados os resumos dos estudos primários e, posteriormente, analisadas e selecionadas as pesquisas de interesse, conforme enfoque temático, período de publicação, idiomas português, inglês ou espanhol. Foram excluídos da pesquisa os artigos que não atenderam aos critérios prévios de inclusão (artigo, pesquisa, idioma e temática). Dessa forma, o corpus do trabalho foi composto por 19 artigos. Resultados: É fato que há a necessidade de reeducação do trabalhador de saúde em relação aos riscos ocupacionais, inclusive sobre a exaustão e os limites do corpo, podendo assim proporcionar uma conscientização e consequentemente minimizar casos de acidentes de trabalho, e, enfim, melhorar a saúde do trabalhador.
\end{abstract}

Palavras-chave: Enfermagem. Riscos ergonômicos. Saúde do Trabalhador.

Submissão: $15 / 03 / 2020$

Aceite: $28 / 09 / 2020$

DOI: $10.47591 / 2674-9203.2020 v 2 n 1 . a r t 1-1-16$

\section{$(1)(9)$}

Este trabalho está licenciado com uma Licença Creative Commons Atribuição-NãoComercial 4.0 Internacional.

\footnotetext{
${ }^{1}$ Acadêmica de Enfermagem na Faculdade Integrada de Santa Maria - FISMA. E-mail: carinesabin.ayres@yahoo.com.br.

${ }^{2}$ Acadêmica de Enfermagem na Faculdade Integrada de Santa Maria - FISMA. E-mail: deisefriedrich@yahoo.com.br.

${ }^{3}$ Mestre em Geomática pela Universidade Federal de Santa Maria - UFSM. Doutora em Enfermagem pela Universidade Federal do Rio Grande - FURG. E-mail: simone.nunes@ fisma.com.br.
} 


\section{INTRODUÇÃO}

0 trabalho é sem dúvida uma atividade extremamente importante, que proporciona ao homem manter suas relações no meio social, sendo capaz de satisfazer suas necessidades mais básicas, além de proporcionar diversos sentimentos e situações. Ao realizar este tipo de atividade, o indivíduo expõe-se aos mais diversos riscos, podendo influenciar diretamente em sua condição de saúde. (NEVES et al., 2011).

Os interesses financeiros muitas vezes não oferecem aos trabalhadores as condições necessárias para o exercício de suas atividades. Isso se torna preocupante, já que para uma melhor eficiência na atuação da equipe de Enfermagem são necessárias condições mínimas de trabalho, como espaço físico adequado, auxílio para transportar paciente de cama ou mudanças de decúbito, além de um ambiente harmônico para minimizar o estresse da profissão. (DUARTE; MAURO, 2010).

O estresse no modo de vida atual tornou-se importante e é reconhecido como um dos riscos ao bem-estar do indivíduo como um todo, sendo por vezes relacionado a alterações no estado de saúde. Como consequência de toda essa problemática, apresenta-se: deficiência no desempenho do profissional, baixa moral, violência no local de trabalho, dentre tantas outras. (GUIDO et al., 2011).

A formação do profissional de saúde ainda é extremamente voltada para que ele adquira conhecimentos que sejam aplicados diretamente aos pacientes. Existe uma distância entre o cuidado ao paciente e o autocuidado do profissional que cuida, sendo uma situação bastante complicada, que vem a favorecer o acometimento de diversos problemas de saúde ao profissional. (PINHEIRO; ZEITOUNE, 2008).

Além disso, nos hospitais, os enfermeiros estão frequentemente expostos a vários fatores de risco no decorrer das suas atividades de trabalho, que vem a contribuir para o desenvolvimento de vários distúrbios. Isso afeta a saúde dos profissionais, e interfere no decorrer da prestação direta de cuidados a pacientes acamados, como a sua mobilização durante a realização da higiene, seu levantamento e transferência. (SERRANHEIRA et al., 2012).

Partindo desse pressuposto, apresenta-se como problema de pesquisa: "O que tem sido produzido cientificamente acerca dos riscos ergonômicos enfrentados pelo enfermeiro?". Com base nesse questionamento, constitui-se o objetivo deste estudo: analisar as produções científicas geradas acerca dos riscos ergonômicos enfrentados pelo enfermeiro através de uma revisão narrativa.

Portanto, a partir do enfoque apresentado, este estudo poderá contribuir para que os profissionais da área da saúde, especialmente o enfermeiro e os acadêmicos de Enfermagem, possam refletir de forma consciente sobre as atitudes perante sua segurança, seu estado de saúde, os riscos ergonômicos e ocupacionais que podem ser prevenidos. 


\section{REVISÃO DE LITERATURA}

0 trabalho é de fato inerente à vida, mas o fator de como ele é executado traz muitas vezes prejuízo para quem o pratica, englobando dificuldades, acarretando em acidentes laborais, adquirindo doenças, expondo-se a riscos, como químicos, biológicos, ergonômicos, ou levando muitas vezes, inclusive, ao óbito. Diante disso, é importante observar se a forma de execução de um determinado trabalho é nociva à saúde do funcionário. (NEVES et al., 2011).

Mundialmente, uma das questões preocupantes com relação à equipe de enfermagem é a escassez de mão de obra, muitas vezes relacionada à falta de qualificação necessária, ou até mesmo ao absenteísmo e à evasão do trabalho. Isso acaba sobrecarregando os profissionais do setor, trazendo riscos laborais a eles. (DE MAGALHÃES et al., 2013).

A Enfermagem tem como característica peculiar a assistência ininterrupta por 24 horas por dia, ou seja, é a profissão que mais tem contato direto com o paciente, e dessa maneira, uma doença crônica evidenciada pode alterar o cotidiano do profissional, sendo considerada uma ameaça, afetando também aos pacientes. (TEIXEIRA; MANTOVANI, 2009).

Sendo assim, os inúmeros riscos advindos da atividade laboral são analisados de acordo com as necessidades, controlando assim, os riscos desnecessários. Dessa forma, a ergonomia exerce a análise dos serviços, máquinas, produtos, ferramentas e sua possível utilização, além de verificar as limitações e capacidades dos funcionários. (DUARTE; MAURO, 2010).

Dentre os riscos ergonômicos evidenciados estão os Distúrbios Osteomusculares relacionadas ao trabalho (DORT), que são uma série de complicações que afetam o aparelho osteomuscular, advindas de vários fatores, inclusive de atividades realizadas em espaços inadequados e disposições incorretas. (SERRANHEIRA et al., 2012).

\section{MÉTODO}

Trata-se de um estudo bibliográfico, o qual propõe fazer um levantamento de produções científicas relacionadas aos riscos ergonômicos enfrentados pelos enfermeiros/ equipe de enfermagem. A questão norteadora para esta pesquisa foi: "O que tem sido produzido cientificamente acerca dos riscos ergonômicos enfrentados pelo enfermeiro?". A justificativa para tal baseia-se na frequência de casos em que profissionais das equipes de enfermagem são expostos a risco laborais que consequentemente trazem danos, muitas vezes severos.

A busca foi realizada entre os meses de outubro e novembro de 2019 , por meio das bases de dados Literatura Latino-Americana e do Caribe em Ciências da Saúde (LILACS), National Library of Medicine National Institutes of Health (Pubmed) e Medical Literature Analysis and Retrievel System Online (Medline). Para tanto, foram utilizados os descritores: "ENFERMAGEM" [Palavras] and ("ERGONOMIA") or "RISCOS OCUPACIONAIS" [Palavras] and "SAÚDE DO TRABALHADOR" [Palavras].

Para estabelecer a amostragem, foi realizada a leitura dos resumos dos estudos primários e, por conseguinte, analisados e selecionadas as pesquisas de 
interesse, conforme enfoque temático, período de publicação, idioma português/inglês/espanhol. Dessa forma, após a análise, foram excluídos da pesquisa artigos por não atenderem aos critérios prévios de inclusão (artigo, pesquisa, idioma e temática). 0 recorte temporal foi baseado no primeiro artigo encontrado nesta busca após o decreto da NR 32, de novembro de 2005, que rege a segurança do trabalho na saúde.

Dessa forma, foram encontrados 17 artigos na base de dados LILACS, mas após a aplicação dos critérios de inclusão e exclusão, restaram 8 artigos para compor o corpus do trabalho. Na base de dados Pubmed, os filtros selecionados foram: textos completos públicos, ensaio controlado randomizado, humanos, adultos de 19 a 44 anos e meia idade de 45 a 64 anos, e dessa maneira, foram encontrados 114 artigos, mas após a aplicação dos critérios de inclusão e exclusão restaram 8 artigos para somar ao corpus do trabalho. Já pela Medline foram encontrados 9 artigos, mas destes, apenas 3 artigos não foram excluídos. Dessa forma, o corpus do trabalho terá no total 19 artigos.

Após a análise do corpus, foram estabelecidas as seguintes categorias temáticas: Riscos Ocupacionais enfrentados pela Enfermagem; Distúrbios Osteomusculares; Resistência ao uso dos EPIs; e Alteração do Ciclo sono-vigília.

\section{ANÁLISE E DISCUSSÃO DOS RESULTADOS}

Inicialmente, foram aplicados os critérios de inclusão e exclusão, após foi realizada uma leitura dos resumos dos artigos encontrados para identificar sua relação com o tema, e organizados nos três quadros a seguir, em ordem cronológica crescente, divididos por bases de dados.

Quadro 1 - Informações sobre os artigos selecionados para a análise da base LILACS

\begin{tabular}{|l|l|}
\hline ANO & 2008 \\
\hline TÍTULO & $\begin{array}{l}\text { Hepatite B: conhecimento e medidas de biossegurança e a saúde do } \\
\text { trabalhador de enfermagem }\end{array}$ \\
\hline OBJETIVO GERAL & $\begin{array}{l}\text { Descrever o conhecimento dos profissionais de enfermagem acerca da } \\
\text { doença hepatite B; analisar as medidas de biossegurança com relação à } \\
\text { hepatite B utilizadas pelos profissionais de enfermagem; e discutir as } \\
\text { implicações do conhecimento acerca da hepatite B e as medidas de } \\
\text { biossegurança para a saúde do trabalhador de enfermagem. }\end{array}$ \\
\hline RESULTADOS & $\begin{array}{l}\text { Constatou-se que a maioria dos profissionais de enfermagem desconhecia as } \\
\text { formas de transmissão da hepatite B; um número significativo de } \\
\text { profissionais de enfermagem não havia recebido treinamento de como } \\
\text { proceder caso houvesse um acidente com material perfurocortante; o } \\
\text { conhecimento das medidas de biossegurança não estava presente em toda } \\
\text { equipe, nem todos as usavam de forma rotineira. }\end{array}$ \\
\hline CONCLUSÕES & $\begin{array}{l}\text { Concluímos que os resultados indicam que alguns profissionais estariam } \\
\text { expostos ao risco de contrair a hepatite B caso ocorresse acidente com } \\
\text { material perfurocortante. }\end{array}$ \\
\hline ANO & $\begin{array}{l}\text { Enfermeiros com doença crônica: as relações com o adoecimento, a } \\
\text { prevenção e o processo de trabalho. }\end{array}$ \\
\hline TÍTULO & $\begin{array}{l}\text { Identificar nos enfermeiros as medidas de prevenção de agravos à saúde NE } \\
\text { presença de doença crônica, analisar a relação entre o conhecimento e suas } \\
\text { atitudes frente a elas e verificar a relação dos fatores de risco com seu } \\
\text { processo de trabalho. }\end{array}$ \\
\hline OBJETIVO GERAL
\end{tabular}




\begin{tabular}{|c|c|}
\hline RESULTADOS & $\begin{array}{l}\text { Trata-se de uma pesquisa quantitativa e descritiva, realizada com } 23 \\
\text { enfermeiros portadores de doenças crônicas, representando } 76,7 \% \text { dos } 30 \\
\text { enfermeiros com diagnóstico de enfermidade crônica em uma Instituição } \\
\text { Hospitalar Federal, sendo } 22 \text { do sexo feminino. }\end{array}$ \\
\hline CONCLUSÕES & $\begin{array}{l}\text { Verificou-se que os enfermeiros aderem aos tratamentos propostos para sua } \\
\text { doença, possuem estratégias efetivas para enfrentar o adoecimento com } \\
\text { mudança do estilo de vida, e relatam fatores no seu ambiente de trabalho } \\
\text { que contribuem para seu agravamento. }\end{array}$ \\
\hline ANO & 2010 \\
\hline TÍTULO & $\begin{array}{l}\text { Análise dos fatores de riscos ocupacionais do trabalho de enfermagem sob a } \\
\text { ótica dos enfermeiros }\end{array}$ \\
\hline OBJETIVO GERAL & $\begin{array}{l}\text { Identificar, na percepção dos enfermeiros chefes de unidades de internação } \\
\text { de um hospital universitário, os riscos ocupacionais a que estão expostos. }\end{array}$ \\
\hline RESULTADOS & $\begin{array}{l}\text { Os resultados evidenciaram que os fatores de risco atuam sobre os } \\
\text { trabalhadores, propiciando um ambiente desfavorável para a realização das } \\
\text { atividades, podendo comprometer a saúde e a vida profissional destes. }\end{array}$ \\
\hline CONCLUSÕES & $\begin{array}{l}\text { A pesquisa proporcionou um diagnóstico referente aos riscos presentes nos } \\
\text { ambientes de trabalho da enfermagem, proporcionando um modo } \\
\text { operatório eficaz com menor risco de acidentes no processo de trabalho, } \\
\text { ambientes menos insalubres e maior satisfação para o profissional e os } \\
\text { clientes. }\end{array}$ \\
\hline ANO & 2011 \\
\hline TÍTULO & Estresse, coping e estado de saúde entre enfermeiros hospitalares \\
\hline OBJETIVO GERAL & $\begin{array}{l}\text { Identificar estressores, nível de estresse dos enfermeiros, estado geral de } \\
\text { saúde e formas de enfrentamento utilizadas pelos enfermeiros no ambiente } \\
\text { de trabalho. }\end{array}$ \\
\hline RESULTADOS & $\begin{array}{l}\text { Em relação às formas de enfrentamento, identificou-se resolução de } \\
\text { problemas como o fator de maior média. }\end{array}$ \\
\hline CONCLUSÕES & $\begin{array}{l}\text { Concluindo, ações educativas devem ser incentivadas, a fim de disponibilizar } \\
\text { ferramentas para que o profissional desenvolva estratégias de coping } \\
\text { resolutivas em seu dia a dia, minimizando o efeito do estresse no seu estado } \\
\text { de saúde e no seu trabalho. }\end{array}$ \\
\hline ANO & 2011 \\
\hline TÍTULO & $\begin{array}{l}\text { Segurança dos trabalhadores de enfermagem e fatores determinantes para } \\
\text { adesão aos equipamentos de proteção individual }\end{array}$ \\
\hline OBJETIVO GERAL & $\begin{array}{l}\text { Analisar as razões, atitudes e crenças dos trabalhadores de enfermagem, } \\
\text { referentes à adesão aos equipamentos de proteção individual. }\end{array}$ \\
\hline RESULTADOS & $\begin{array}{l}\text { Identificaram-se várias barreiras que interferem nas questões de segurança } \\
\text { e proteção individual como comunicação, sobrecarga do trabalho, estrutura } \\
\text { física, acessibilidade aos equipamentos de proteção e aspectos } \\
\text { organizacionais e gerenciais. }\end{array}$ \\
\hline CONCLUSÕES & $\begin{array}{l}\text { A adesão aos equipamentos de proteção é determinada tanto pelo contexto } \\
\text { vivenciado no ambiente de trabalho, como, também, por valores e crenças } \\
\text { individuais, mas a decisão sobre o uso dos equipamentos de proteção é } \\
\text { individual. }\end{array}$ \\
\hline ANO & 2011 \\
\hline TÍTULO & Trabalho noturno e a repercussão na saúde dos enfermeiros \\
\hline OBJETIVO GERAL & $\begin{array}{l}\text { Apresentar e discutir as alterações na saúde percebidas por enfermeiros do } \\
\text { período noturno }\end{array}$ \\
\hline RESULTADOS & $\begin{array}{l}\text { Os resultados evidenciaram que } 27 \text { enfermeiros percebem alterações na } \\
\text { saúde como a má qualidade no sono/repouso, o cansaço/desgaste, entre } \\
\text { outras. Por outro lado, há a conveniência de trabalhar no período noturno } \\
\text { para continuar os estudos ou a possibilidade de conciliar o segundo } \\
\text { emprego. }\end{array}$ \\
\hline
\end{tabular}




\begin{tabular}{|c|c|}
\hline CONCLUSÕES & $\begin{array}{l}\text { Pôde-se concluir que é necessária uma compreensão do trabalhador sobre } \\
\text { os limites do seu corpo para que a realização da atividade não interfira no } \\
\text { processo saúde-doença e não comprometa a assistência prestada. }\end{array}$ \\
\hline ANO & 2012 \\
\hline TÍTULO & Lombalgias e trabalho hospitalar em enfermeiro(a)s \\
\hline OBJETIVO GERAL & $\begin{array}{l}\text { Identificar e analisar a prevalência de sintomas osteomusculares na região } \\
\text { lombar relacionados ao trabalho dos enfermeiros(as) em contexto } \\
\text { hospitalar. }\end{array}$ \\
\hline RESULTADOS & $\begin{array}{l}\text { Os resultados evidenciam uma prevalência elevada de sintomas de DORT na } \\
\text { região lombar presentes nos últimos } 12 \text { meses (60,9\%) e nos últimos } 7 \text { dias } \\
(48,8 \%) \text {. A presença desses sintomas parece estar associada a algumas } \\
\text { variáveis organizacionais e profissionais, tais como: a categoria profissional; } \\
\text { o tipo de trabalho; o tipo de serviço e algumas tarefas, das quais os cuidados } \\
\text { de higiene e conforto na cama foram aquelas com maior relação com a } \\
\text { sintomatologia. }\end{array}$ \\
\hline CONCLUSÕES & $\begin{array}{l}\text { Conclui-se, no presente estudo, que as tarefas e as características das } \\
\text { atividades reais de trabalho são os fatores com maior influência na presença } \\
\text { de sintomatologia osteomuscular na zona lombar e, por isso, é } \\
\text { possivelmente aí que devem incidir as intervenções tendentes a prevenir as } \\
\text { DORT e a garantir a saúde e segurança dos enfermeiros no local de trabalho. }\end{array}$ \\
\hline ANO & 2013 \\
\hline TÍTULO & $\begin{array}{l}\text { Carga de trabalho da equipe de enfermagem e segurança do paciente: estudo } \\
\text { com método misto na abordagem ecológica restaurativa. }\end{array}$ \\
\hline OBJETIVO GERAL & $\begin{array}{l}\text { Analisar a carga de trabalho da equipe de enfermagem e sua potencial } \\
\text { relação com a segurança do paciente em unidades de internação das áreas } \\
\text { clínica e cirúrgica de um hospital universitário. }\end{array}$ \\
\hline RESULTADOS & $\begin{array}{l}\text { A etapa quantitativa inicial do estudo sugere que o aumento do número de } \\
\text { pacientes designados para a equipe de enfermagem implica em aumento das } \\
\text { taxas de queda do leito, infecções relacionadas ao cateter vascular central, } \\
\text { rotatividade de profissionais e absenteísmo. Durante a etapa qualitativa } \\
\text { subsequente, a equipe de enfermagem destacou os cuidados relacionados à } \\
\text { administração de medicação, banho de leito e transporte de pacientes, como } \\
\text { aqueles que mais repercutem na carga de trabalho e mais representam os } \\
\text { riscos para a segurança do paciente, dos profissionais e do ambiente. }\end{array}$ \\
\hline CONCLUSÕES & $\begin{array}{l}\text { Os achados deste estudo evidenciaram associações significativas entre carga } \\
\text { de trabalho e a segurança dos pacientes. Observa-se que os quadros de } \\
\text { pessoal com menos pacientes apresentaram os melhores indicadores de } \\
\text { qualidade assistencial e gerencial de segurança do paciente. Além disso, os } \\
\text { princípios do pensamento ecológico e restaurativo contribuíram para a } \\
\text { compreensão de alguns dos aspectos envolvidos nessa intricada relação, a } \\
\text { partir dos olhares dos próprios profissionais e também promoveram } \\
\text { abordagem participativa para o estudo desse tema. }\end{array}$ \\
\hline
\end{tabular}

Fonte: As autoras (2019).

Quadro 2 - Informações sobre os artigos selecionados para a análise da base PubMed

\begin{tabular}{|l|l|}
\hline ANO & 2015 \\
\hline TÍTULO & $\begin{array}{l}\text { Protegendo e promovendo a saúde mental dos enfermeiros no ambiente } \\
\text { hospitalar: é custo-efetivo do ponto de vista do empregador? }\end{array}$ \\
\hline OBJETIVO GERAL & $\begin{array}{l}\text { Enfermeiros têm risco elevado de transtornos de estresse, ansiedade e } \\
\text { transtornos depressivos, podendo então se tornar menos produtivos. }\end{array}$ \\
\hline RESULTADOS & $\begin{array}{l}\text { Subtrair os custos de intervenção das compensações de custo devido ao } \\
\text { absenteísmo e presenteísmo reduzidos resultou em uma economia líquida } \\
\text { de } 244 \text { euros por enfermeiro, quando se considera apenas o absentismo, e } \\
\text { de 651 euros, quando se considera também o presenteísmo. }\end{array}$ \\
\hline CONCLUSÕES & $\begin{array}{l}\text { Dentro de meio ano, o custo de oferecer a intervenção preventiva foi mais do } \\
\text { que recuperado. Oferecer a intervenção preventiva representa um caso de } \\
\text { negócios favorável, visto da perspectiva do empregador. }\end{array}$ \\
\hline
\end{tabular}




\begin{tabular}{|c|c|}
\hline ANO & 2016 \\
\hline TÍTULO & $\begin{array}{l}\text { O impacto de uma intervenção ergonômica sobre fatores psicossociais e } \\
\text { sintomas musculoesqueléticos entre atendentes de hospitais tailandeses }\end{array}$ \\
\hline OBJETIVO GERAL & $\begin{array}{l}\text { Este estudo avaliou os efeitos de uma intervenção ergonômica sobre } \\
\text { distúrbios musculoesqueléticos e fatores de risco psicossociais. }\end{array}$ \\
\hline RESULTADOS & $\begin{array}{l}\text { O problema mais comumente relatado entre os atendentes do hospital foi } \\
\text { encontrado para sintomas lombares ( } 82 \%) \text {. O estudo encontrou diferenças } \\
\text { significativas nas taxas de prevalência de condições musculoesqueléticas } \\
\text { relatadas no braço, parte superior das costas e região inferior das costas } \\
\text { antes e depois da intervenção. Os resultados mostraram que os fatores de } \\
\text { risco psicossociais foram afetados pela intervenção. }\end{array}$ \\
\hline CONCLUSÕES & $\begin{array}{l}\text { Foram observados resultados positivos após a intervenção no ambiente de } \\
\text { trabalho, principalmente no que diz respeito à redução dos fatores de risco do } \\
\text { ambiente físico de trabalho para distúrbios musculoesqueléticos e ao aumento dos } \\
\text { fatores de promoção do ambiente psicossocial de trabalho. }\end{array}$ \\
\hline ANO & \begin{tabular}{|l|}
2017 \\
\end{tabular} \\
\hline TÍTULO & $\begin{array}{l}\text { Processos, barreiras e facilitadores para a implementação de um programa } \\
\text { participativo de ergonomia entre trabalhadores idosos }\end{array}$ \\
\hline OBJETIVO GERAL & $\begin{array}{l}\text { Investigar os processos de um programa participativo de ergonomia entre } \\
594 \text { trabalhadores idosos com ênfase nos fatores de risco identificados para } \\
\text { lombalgia e soluções, e revelar barreiras e facilitadores para sua } \\
\text { implementação. }\end{array}$ \\
\hline RESULTADOS & $\begin{array}{l}\text { Sessenta e nove por cento dos fatores de risco identificados eram } \\
\text { ergonômicos físicos, } 24 \% \text { eram organizacionais e } 7 \% \text { eram fatores de risco } \\
\text { psicossociais. A maioria das soluções foi organizacional (55\%), seguida de } \\
\text { soluções físicas (43\%) e psicossociais (2\%). Fatores internos (por exemplo, } \\
\text { equipe ou gestão) constituíram } 47 \% \text { das barreiras e } 75 \% \text { dos facilitadores. } \\
\text { Fatores externos (por exemplo, tempo, recursos financeiros, colaboração } \\
\text { com residentes ou parentes) constituíram } 53 \% \text { das barreiras e } 25 \% \text { dos } \\
\text { facilitadores. }\end{array}$ \\
\hline CONCLUSÕES & $\begin{array}{l}\text { Este estudo revelou os processos e a implementação de um programa } \\
\text { participativo de ergonomia entre os trabalhadores idosos. As descobertas } \\
\text { podem ser transferidas para trabalhadores, locais de trabalho, profissionais } \\
\text { de saúde e segurança e pesquisadores para melhorar futuros programas de } \\
\text { ergonomia participativa. }\end{array}$ \\
\hline ANO & 2017 \\
\hline TÍTULO & $\begin{array}{l}\text { Eficácia de um monitor lombo-pélvico e dispositivo de feedback para mudar } \\
\text { o comportamento postural: um protocolo para o ensaio clínico controlado } \\
\text { randomizado ELF }\end{array}$ \\
\hline OBJETIVO GERAL & $\begin{array}{l}\text { Avaliar a eficácia de um dispositivo de feedback postural lombo-pélvico para } \\
\text { mudar o comportamento postural em um grupo de profissionais de saúde. }\end{array}$ \\
\hline RESULTADOS & $\begin{array}{l}\text { A medida do resultado primário será o comportamento postural (excedendo } \\
\text { os limites). As medidas do resultado secundário serão a incidência de } \\
\text { lombalgia, deficiência relatada pelo participante e adesão. Após a avaliação } \\
\text { inicial, iremos atribuir aleatoriamente aos participantes a } 1 \text { de } 2 \text { braços de } \\
\text { intervenção: um grupo de feedback e um grupo de controle sem feedback. } \\
\text { Vamos comparar as diferenças entre os grupos de mudanças no } \\
\text { comportamento postural usando uma análise de modelo de efeito misto de } \\
\text { medidas repetidas de covariância (ANCOVA) em } 6 \text { semanas. }\end{array}$ \\
\hline CONCLUSÕES & $\begin{array}{l}\text { A postura é um fator de risco modificável para distúrbios lombares. As } \\
\text { descobertas do ensaio ELF irão informar o desenho de futuros ensaios } \\
\text { clínicos avaliando a eficácia da tecnologia vestível na minimização da } \\
\text { postura perigosa durante as atividades da vida diária em pacientes com } \\
\text { distúrbios lombares. }\end{array}$ \\
\hline ANO & 2019 \\
\hline
\end{tabular}




\begin{tabular}{|c|c|}
\hline TÍTULO & $\begin{array}{l}\text { A identificação precoce de estresse relacionado ao trabalho, combinada com } \\
\text { o feedback na consulta de GP, evita licenças médicas nos } 12 \text { meses } \\
\text { seguintes? um ensaio clínico randomizado em atenção primária à saúde }\end{array}$ \\
\hline OBJETIVO GERAL & $\begin{array}{l}\text { Avaliar se o uso da intervenção breve Work Stress Questionnaire (WSQ), } \\
\text { incluindo feedback do médico de clínica geral (GP), teve um impacto sobre } \\
\text { o nível de absentismo por doença. }\end{array}$ \\
\hline RESULTADOS & $\begin{array}{l}\text { Os dias médios registrados para o grupo de intervenção WSQ e o grupo de } \\
\text { controle foram } 39 \text { e } 45 \text { dias brutos, respectivamente, e } 31 \text { e } 39 \text { dias líquidos, } \\
\text { respectivamente (ns). Não houve diferença estatisticamente significativa } \\
\text { para o número de episódios de licença médica, ou tempo para o primeiro dia } \\
\text { do episódio de licença médica foi encontrada entre os grupos. }\end{array}$ \\
\hline CONCLUSÕES & $\begin{array}{l}\text { São necessárias mais pesquisas sobre métodos para identificar, aconselhar } \\
\text { e tratar precocemente as pessoas com estresse relacionado ao trabalho na } \\
\text { atenção primária à saúde e sobre como e quando os GPs e outros } \\
\text { profissionais da atenção primária à saúde podem ser treinados para } \\
\text { compreender este risco de licença médica devido ao trabalho-estresse } \\
\text { relacionado, sobre como evitá-lo e como aconselhar e tratar funcionários em } \\
\text { risco. }\end{array}$ \\
\hline ANO & 2019 \\
\hline TÍTULO & $\begin{array}{l}\text { Intervenção ocupacional precoce para pessoas com dor lombar em trabalhos } \\
\text { fisicamente exigentes: um ensaio clínico randomizado }\end{array}$ \\
\hline OBJETIVO GERAL & $\begin{array}{l}\text { Testar se as pessoas com dor lombar (LBP) em empregos fisicamente } \\
\text { exigentes e em risco de licença médica obtêm benefício adicional de uma } \\
\text { intervenção complexa de } 3 \text { meses que envolve consultas de medicina } \\
\text { ocupacional, uma avaliação relacionada ao trabalho e plano de intervenção } \\
\text { no local de trabalho, uma visita opcional ao local de trabalho e um programa } \\
\text { de atividade física, em uma única consulta hospitalar e uma ressonância } \\
\text { magnética. }\end{array}$ \\
\hline RESULTADOS & $\begin{array}{l}\text { Uma análise de intenção de tratar de licença médica em } 6 \text { meses não } \\
\text { mostrou diferença significativa entre os grupos (diferença média em dias } \\
\text { sugestivamente em favor de nenhuma intervenção adicional: } 3,50 \text { [IC 95\% - } \\
5,08 \text { a 12,07], P = 0,42). Ambos os grupos mostraram melhorias } \\
\text { significativas na pontuação média de dor (NRS), deficiência (RMDQ), } \\
\text { crenças de medo de evitar atividades físicas e trabalho (FABQ) e QVRS física } \\
\text { (resumo do componente físico SF-36); não houve diferenças significativas } \\
\text { entre os grupos em qualquer resultado secundário. Não houve melhora } \\
\text { estatisticamente significativa na dor neuropática (pontuação PDQ), QVRS } \\
\text { mental (resumo do componente mental SF-36) e capacidade autoavaliada } \\
\text { de permanecer no trabalho. }\end{array}$ \\
\hline CONCLUSÕES & $\begin{array}{l}\text { Quando recebiam uma única consulta hospitalar e ressonância magnética, as } \\
\text { pessoas em empregos fisicamente exigentes em risco de licença médica } \\
\text { devido à lombalgia não se beneficiavam de uma intervenção ocupacional } \\
\text { adicional complexa. Intervenções ocupacionais destinadas a limitar os } \\
\text { obstáculos biopsicológicos (por exemplo, crenças e comportamentos de } \\
\text { evitar o medo), barreiras no local de trabalho e barreiras do sistema } \\
\text { parecem essenciais para reduzir as licenças médicas em pacientes com } \\
\text { lombalgia. Este estudo indica que esses obstáculos e barreiras podem ser } \\
\text { superados com cuidados habituais completos. }\end{array}$ \\
\hline ANO & 2019 \\
\hline TÍTULO & Terapia assistida por caninos melhora o bem-estar em enfermeiras \\
\hline OBJETIVO GERAL & $\begin{array}{l}\text { Avaliar se a terapia assistida por animais (TAA) com a presença de um cão } \\
\text { afeta o nível de estresse de enfermeiras. }\end{array}$ \\
\hline RESULTADOS & $\begin{array}{l}\text { Os resultados demonstraram o efeito da redução dos níveis de cortisol na } \\
\text { Condição } \mathrm{C} \text {, onde a AAT foi incluída }(\mathrm{p}=0,02) \text { apenas em enfermeiras } \\
\text { recrutadas no departamento de } \mathrm{MI}<\mathrm{C} \text {. }\end{array}$ \\
\hline CONCLUSÕES & $\begin{array}{l}\text { Propomos incluir AAT com um cão em instalações de saúde onde as } \\
\text { enfermeiras correm um alto risco de estresse. }\end{array}$ \\
\hline
\end{tabular}




\begin{tabular}{|l|l|}
\hline ANO & 2019 \\
\hline TÍTULO & $\begin{array}{l}\text { Intervenção multifacetada para a prevenção e tratamento da dor } \\
\text { musculoesquelética na equipe de enfermagem: resultados de um ensaio } \\
\text { clínico randomizado controlado }\end{array}$ \\
\hline OBJETIVO GERAL & $\begin{array}{l}\text { Avaliar uma intervenção multifacetada para prevenir e gerenciar DME em } \\
\text { dois hospitais. }\end{array}$ \\
\hline RESULTADOS & $\begin{array}{l}\text { Oito grupos foram randomizados, incluindo 473 enfermeiras e auxiliares de } \\
\text { enfermagem. Aos 12 meses, o grupo de intervenção apresentou uma } \\
\text { diminuição estatisticamente significativa do risco de dor no pescoço, ombros } \\
\text { e parte superior das costas, em comparação com o grupo controle (OR = } \\
\text { 0,37; IC 95\% = 0,14-0,96). Também foi observada redução da lombalgia, } \\
\text { embora não estatisticamente significativa. Não encontramos diferenças em } \\
\text { relação ao funcionamento do trabalho e à incidência e duração das ausências } \\
\text { por doença. }\end{array}$ \\
\hline CONCLUSÕES & $\begin{array}{l}\text { A intervenção foi eficaz na redução da dor no pescoço, ombros e parte } \\
\text { superior das costas. Nossos resultados, embora modestos, sugerem que as } \\
\text { intervenções para prevenir e gerenciar MSP precisam de uma abordagem } \\
\text { multifatorial, incluindo os três níveis de prevenção, e enquadrada no modelo } \\
\text { biopsicossocial. }\end{array}$ \\
\hline
\end{tabular}

Fonte: As autoras (2019).

Quadro 3 - Informações sobre os artigos selecionados para a análise da base MEDLINE

\begin{tabular}{|c|c|}
\hline ANO & 2007 \\
\hline TÍTULO & $\begin{array}{l}\text { Organização tecnológica do trabalho em um pronto atendimento e a } \\
\text { autonomia do trabalhador de enfermagem }\end{array}$ \\
\hline OBJETIVO GERAL & $\begin{array}{l}\text { Analisar a organização dos processos de trabalho em um serviço de pronto } \\
\text { atendimento e a autonomia do trabalhador de enfermagem na prestação de } \\
\text { cuidados ao usuário. }\end{array}$ \\
\hline RESULTADOS & $\begin{array}{l}\text { Constatou-se que o processo de trabalho está organizado com a finalidade } \\
\text { de tratar a queixa principal, tendo como ação nuclear a consulta médica. A } \\
\text { organização tecnológica do trabalho coloca o médico como detentor de } \\
\text { poder, seguido da enfermeira, nos seus espaços de poder e autonomia, que } \\
\text { é pouco exercida pelos demais agentes. }\end{array}$ \\
\hline CONCLUSÕES & $\begin{array}{l}\text { O trabalho da enfermagem é fundamental, perpassando todos os espaços de } \\
\text { atendimento e interligando as ações, mas se caracteriza como um trabalho } \\
\text { auxiliar das atividades do pronto atendimento. }\end{array}$ \\
\hline ANO & 2007 \\
\hline TÍTULO & $\begin{array}{l}\text { Ser trabalhador de enfermagem da Unidade de Centro de Material: uma } \\
\text { abordagem fenomenológica }\end{array}$ \\
\hline OBJETIVO GERAL & $\begin{array}{l}\text { Compreender a experiência dos trabalhadores de enfermagem da Unidade } \\
\text { de Centro de Material (UCM) de um hospital de Londrina, utilizando a } \\
\text { pesquisa qualitativa fenomenológica. }\end{array}$ \\
\hline RESULTADOS & $\begin{array}{l}\text { As quatro categorias que configuram a estrutura geral do fenômeno } \\
\text { investigado Ser trabalhador de Enfermagem da UCM são: Falando do } \\
\text { ingresso na UCM; Falando sobre o trabalho desenvolvido na UCM; } \\
\text { Vivenciando as dificuldades e Superando obstáculos. }\end{array}$ \\
\hline CONCLUSÕES & $\begin{array}{l}\text { O acompanhamento de uma equipe multidisciplinar que tenha como meta } \\
\text { assistir ao trabalhador da área da saúde pode realizar um grande trabalho. } \\
\text { O enfermeiro, o psicólogo, o fisioterapeuta, o assistente social são exemplos } \\
\text { de profissionais que podem contribuir na assistência destes trabalhadores. }\end{array}$ \\
\hline ANO & 2010 \\
\hline TÍTULO & $\begin{array}{l}\text { Biossegurança e a enfermagem nos cuidados clínicos: Biossegurança e a } \\
\text { enfermagem nos cuidados clínicos: contribuições para a saúde do } \\
\text { trabalhador }\end{array}$ \\
\hline OBJETIVO GERAL & $\begin{array}{l}\text { Investigar concepções e práticas de técnicos em enfermagem acerca da } \\
\text { biossegurança e sua interface com os riscos biológicos, desenvolvido com }\end{array}$ \\
\hline
\end{tabular}




\begin{tabular}{|l|l|}
\hline & $\begin{array}{l}\text { vinte trabalhadores de uma unidade de cuidado clínico, de um hospital do } \\
\text { interior do Rio Grande do Sul. }\end{array}$ \\
\hline RESULTADOS & $\begin{array}{l}\text { A negligência dos trabalhadores quanto ao uso de Equipamentos de } \\
\text { Proteção individual e a sobrecarga de trabalho são fatores de risco para os } \\
\text { acidentes com material biológico. }\end{array}$ \\
\hline CONCLUSÕES & $\begin{array}{l}\text { Sugerem-se parcerias entre os atores envolvidos no cuidado para a } \\
\text { construção de ambientes saudáveis e responsabilização por negligências à } \\
\text { biossegurança. }\end{array}$ \\
\hline
\end{tabular}

Fonte: As autoras (2019).

Após análise de cada um dos artigos científicos descritos nos quadros acima, as discussões foram subdividas nas seguintes categorias: Riscos Ocupacionais enfrentados pela Enfermagem; Distúrbios Osteomusculares; Resistência ao uso dos EPIs; e Alteração do Ciclo sono-vigília.

\subsection{RISCOS OCUPACIONAIS ENFRENTADOS PELA ENFERMAGEM}

0 profissional de enfermagem está constantemente exposto a um tipo específico de estresse, o "psicogênico", que é quando um indivíduo está exposto a desafios psicológicos ou sociais que levam à perturbação de seu estado psicológico, bem-estar; além de muitas vezes enfrentarem esta problemática devido à própria estrutura de trabalho (turnos de trabalho de 12 horas, alternando turnos diurnos e noturnos, frequentemente o trabalho é fisicamente extenuante e há o envolvimento com pacientes doentes e moribundos, bem como com suas famílias - sendo todos fatores estressantes que o pessoal de saúde deve enfrentar. (MACHOVA et al., 2019).

0 estresse relacionado ao trabalho apresenta-se como um grave risco para o desenvolvimento de problemas de saúde mental, como sintomas depressivos, transtornos de humor e ansiedade e transtornos musculoesqueléticos. (HOLMGREN et al., 2019).

0 ambiente de trabalho da equipe de enfermagem é, em muitos casos, insalubre e estressante, além da baixa remuneração, de pouco intervalo para descanso e para as refeições, da sobrecarga de trabalho, e muitas vezes até o duplo emprego. Adicionado a isso, prestam cuidados ininterruptos, diante de pacientes graves, ou à beira da morte, lidam constantemente com a dor, com o sofrimento mental, e ainda estão expostos a produtos químicos (desinfetantes, esterilizantes, medicamentos, agentes físicos e biológicos). (DUARTE; MAURO, 2010).

Aliado a isso, há também constantes riscos físicos, como temperatura excessiva, ou até iluminação ineficiente. Diante de todos os fatores que interferem na atividade laboral, algumas instituições já estão investindo nas estruturas físicas, em recursos materiais e tecnológicos, assim como, qualificando e aumentando o quadro de pessoal, para cada vez mais melhorar a qualidade do cuidado. (LOPES et al., 2007).

Além disso, agravos na saúde do enfermeiro merecem destaque importante. Isso devido à exposição a desgaste contínuo, perda do bem-estar, estresse, sobrecarga de trabalho, atritos nas relações interpessoais, falta de autonomia, excesso de autoridade dos supervisores no trabalho, longas jornadas de trabalho, elevada tensão emocional, frequência do trabalho duplo e pouco tempo para realizar tantas tarefas. Todos esses fatores podem ocasionar acidentes no local de trabalho, doença crônica ou até a morte prematura dos profissionais. (SILVA et al., 2011). 
Referente à falta de autonomia, a equipe de enfermagem controla as demandas dos setores, administra conflitos, serve de guardiãs das normas e da política institucional, mas mesmo assim é submissa em seu local de trabalho. Embora tenham movimentos na busca de conseguir maior autonomia, essa ainda é muito tênue; mesmo assim, devem cada vez mais utilizar sua competência, conhecimento e sensibilidade para continuar na prática do cuidado, e conseguir o tão merecido reconhecimento. (MARQUES; LIMA, 2008).

Todos estes fatores abalam a saúde mental dos profissionais da saúde, e quando há um desequilíbrio na saúde mental, consequentemente ocorre um prejuízo não só na rotina do próprio profissional, como dos pacientes e também no financeiro, ou seja, ao empregador, pois acometem ao absenteísmo, ocorre uma limitada rotatividade de pessoal, e redução do desempenho nas suas funções, evidenciando em uma sobrecarga nos serviços. Sendo assim, é importante e útil ter uma detecção precoce de sinais e um feedback personalizado, melhorando a relação custo-benefício, favorecendo tanto empregado como empregador. (NOBEN et al., 2015).

\subsection{DISTÚRBIOS OSTEOMUSCULARES}

Os Distúrbios Musculoesqueléticos relacionadas ao Trabalho (DORT) são motivados por alguns fatores de risco, como levantamento de cargas pesadas, tarefas repetitivas e posturas de trabalho inadequadas, períodos longos de exposição a uma determinada tarefa, que exigem muito do profissional, tanto fisicamente como psicologicamente. As maiores taxas de prevalências dos sintomas são referidas como sendo nos braços e na parte superior e inferior das costas (lombalgias). (CHANCHAI et al., 2016).

Podemos dividir os Distúrbios Osteomusculares (DORT) em dois grupos: nos que resultam de atividades de mobilização e transporte manual de cargas, com efeito na coluna vertebral, mais precisamente na região lombar; e os que estão relacionados com a realização de tarefas estáticas ou repetitivas, com ou sem aplicação de força, com danos na maioria os membros superiores. (SERRANHEIRA, 2012).

A dor lombar (LBP) é um distúrbio musculoesquelético comum, caro (diante do ponto de vista custo-benefício) e incapacitante, e é prevalente em profissionais de saúde, (por exemplo, enfermeiras, fisioterapeutas e cuidadoras). (MILOSAVLJEVIC; ABBOTT, 2017).

Enfermeiros e auxiliares de enfermagem têm alto risco de desenvolver dores musculoesqueléticas (MSP). Esse tipo de dor é uma característica muito comum dos distúrbios musculoesqueléticos (MSDs) que vem afetando pessoas ao longo da vida em todas as regiões do mundo. Os profissionais da área da saúde, em especial os enfermeiros, são um grupo ocupacional com alto risco de desenvolver MSP; fruto da alta exposição ao levantamento manual de pacientes pesados. (SOLER-FONT et al., 2019).

Percebe-se que um processo de ergonomia participativa pode ajudar a estimular os trabalhadores a se envolverem na gestão do próprio trabalho, diminuindo, assim, os fatores de risco relacionados ao desenvolvimento de suas 
atividades laborais, auxiliando na melhorara de sua saúde. (RASMUSSEN et al., 2016).

Para trabalhadores com lombalgia, o exercício físico parece reduzir o número de recorrências de lombalgia ou prolongar o tempo para a recorrência, além de auxiliarem na saúde mental para sua distração e motivação, para que o profissional possa voltar as suas atividades, evitando inclusive o sedentarismo do mesmo, enquanto se recupera. (HANSEN et al., 2019).

\subsection{RESISTÊNCIA AO USO DOS EPIS}

A equipe de enfermagem, por estar constantemente em contato com os pacientes, está sujeita a riscos laborais, e a Norma Regulamentadora número 32 (NR 32), instituída pelo Ministério do Trabalho e Emprego, estabelece diretrizes para implementação de medidas de proteção à saúde e segurança desses trabalhadores. Ela trata dos riscos biológicos; dos riscos químicos; dos resíduos; das radiações ionizantes; das lavanderias; da limpeza e conservação; e da manutenção de máquinas e equipamentos em serviços que prestam assistência à saúde. (GALLAS; FONTANA, 2010).

Os riscos de agressão e agitação dos pacientes são determinantes de acidentes laborais. Além disso, ainda há a negligência por parte do uso dos Equipamentos de Proteção Individual (EPIs), e fatores como a autoconfiança, o descuido e a pressa, além do desconforto causado por eles, o que faz com que muitos profissionais acabem trabalhando sem fazer seu uso, e muitos, entretanto, acabam por não usar os EPIs adequados pela falta de disponibilidade. (GALLAS; FONTANA, 2010).

A adesão ao uso de medidas de proteção no ambiente de trabalho está ligada à percepção da exposição dos riscos e da sua susceptibilidade. Entretanto, o fato de os profissionais terem conhecimento sobre os riscos não é garantia, ou seja, mesmo sabendo dos riscos, muitas vezes a adesão não é efetiva, o que sinaliza a necessidade de ações para mudar essa realidade. (NEVES, 2011).

Embora o uso de EPIs seja normatizado, em grande parte dos cenários de prestação de cuidados de enfermagem ainda são negligenciadas as normas de biossegurança. Mesmo que seja recomendado o uso dos EPIs sempre que o profissional entrar em contato com o paciente, muitos só os utilizam quando o diagnóstico é conhecido, e isso é preocupante, já que estudos mostram que uma das maiores causas de acidentes de trabalho é a falta do uso desses equipamentos. (GALLAS; FONTANA, 2010).

Esses fatores agravam-se ainda mais quando há precariedade na infraestrutura, aspectos organizacionais do trabalho, falta de conhecimento devido à não existência de educação permanente, como também com a sobrecarga de trabalho, o estresse, o cansaço físico e a falta de tempo. (NEVES et al., 2011).

\subsection{ALTERAÇ̃̃O DO CICLO SONO-VIGÍLIA}

A redução dos movimentos musculares esqueléticos, a lentificação do metabolismo e a diminuição da consciência são características do sono. Além disso, a sonolência é causada pela liberação, ao anoitecer, do hormônio melatonina pela 
glândula pineal, de modo que a restauração se faz essencial e importante, inclusive para a memória. (SILVA et al., 2011).

Estudos mostram que muitos enfermeiros preferem o trabalho noturno como forma de prestar o cuidado ininterrupto e consequentemente atender à demanda da população, citada também que a interação da equipe é mais afetiva. Isso acaba alterando o equilíbrio biológico, hábitos alimentares e do sono, ocasionando perda de atenção, acumulação de erros, afastamento familiar, sensação de isolamento, desordenamento do ritmo circadiano. (SILVA et al., 2011).

Muitos profissionais, para se esquivar do sono, usufruem do uso de bebidas cafeinadas, certas drogas, medicamentos e descongestionantes nasais, e o resultado é a insônia. Entretanto, trabalhando no período noturno, o sono muitas vezes se acumula, e isso pode desencadear a diminuição da capacidade mental e o cansaço inevitável, sendo, portanto, um transtorno para esses profissionais. (SILVA et al., 2011).

A alteração do ciclo sono-vigília entre tantas consequências ocasiona uma má qualidade do sono, desgaste físico e psicológico, ganho de peso ponderal, hipertensão, mal-estar gástrico, impossibilidade de prática de atividades físicas, práticas de lazer, lombalgias recorrentes, entres outros prejuízos à saúde. (NEVES et al., 2011).

Dessa forma o trabalhador do período da noite precisa ter a consciência de que deve respeitar os limites físicos de seu corpo, para que não tenha intercorrências no processo saúde-doença, e para que dessa forma, a qualidade da assistência não seja comprometida. (SILVA et al., 2011).

À vista disso, estudos sugerem que os trabalhadores desse turno consumam alimentos mais leves nos plantões, que evitem o açúcar em excesso, consumo de alimentos fritos, que restrinjam o consumo de café e realizem atividades físicas, com o objetivo de minimizar as repercussões do trabalho em sua saúde. (SILVA et al., 2011).

\section{CONSIDERAÇÕES FINAIS}

Sob o ponto de vista prevencionista, há necessidade de reeducação do trabalhador de saúde em relação aos riscos ocupacionais. Assim como também de uma reestruturação nos currículos das escolas que formam estes profissionais. Isso para reforçar a importância e a necessidade de se discutirem tais questões na formação do enfermeiro, incluindo a de um treinamento permanente, visando aumentar seus conhecimentos quanto à tomada de decisão correta em caso de exposição às secreções corporais, para minimizar as consequências desta exposição.

Além disso, poderia ser adotada a estratégia do "empoderamento" na equipe de enfermagem; a responsabilidade pela resolução dos problemas e a tomada de decisões que tradicionalmente era reservada somente para os supervisores passaria a ser dividida com a equipe. A promoção da saúde da equipe de enfermagem não seria de responsabilidade dos supervisores, mas de todos os componentes da equipe.

Estudos mostram que muitos enfermeiros melhoram a qualidade de saúde ao desviarem seus pensamentos nas horas de folga ou descanso para atividades religiosas, familiares, sociais, e acabam diminuindo a carga horária para evitar 
exposição ao estresse e controlar também a agitação. Além disso, a maioria relata melhorar ao praticar atividades físicas.

Portanto, a equipe ou o profissional em si precisa conhecer os limites do seu corpo e saber à hora de descansar. Seria importante, também, a implementação de programas de assistência à saúde do trabalhador. Inclusive, seria interessante incentivar ações educativas para minimizar o estresse e, assim, tornar o ambiente de trabalho mais produtivo e satisfatório, possibilitando a segurança ao profissional da área de saúde e ao paciente.

\section{LIMITAÇÕES E SUGESTÕES DE NOVOS ESTUDOS}

\subsection{LIMITACÕES DO TRABALHO}

A equipe de enfermagem tem uma interação muito direta com o público, sendo assim, é considerada uma das mais estressantes e com altos índices de riscos ergonômicos. Diante dessas circunstâncias, a pesquisa bibliográfica possui fatores limitantes que devem ser analisados.

Uma das limitações desta pesquisa exploratória é que alguns artigos não foram encontrados na íntegra. Muitos deles abordam a equipe de enfermagem, generalizando, não sendo apresentada distinção entre os profissionais que englobam uma equipe de enfermagem.

Outra questão relevante foi o tamanho reduzido da amostra, permitindo avaliar apenas os resultados encontrados para essa população. Inclusive, o critério para o recorte temporal foi baseado no primeiro artigo encontrado nesta busca após o decreto da Norma Regulamentadora 32, de novembro de 2005, que rege a segurança do trabalho na saúde.

\subsection{SUGESTÕES DE NOVOS ESTUDOS}

A necessidade de reeducação do trabalhador da saúde é um fato. Há um esquecimento do autocuidado do profissional que cuida, acrescentado de esforços repetitivos, postura inadequada, excesso de trabalho, falta de autonomia e, inclusive, atrito nas relações interpessoais. Este contexto proporciona um desgaste contínuo, possibilitando o desenvolvimento de patologias ou até mesmo o padecimento deste trabalhador.

Nesta situação, esta revisão literária surgiu proveniente do objetivo de analisar as produções científicas produzidas acerca dos riscos ergonômicos enfrentados pelo enfermeiro através de uma revisão narrativa, a partir da questão norteadora: "O que tem sido produzido cientificamente acerca dos riscos ergonômicos enfrentados pelo enfermeiro?"

Diante disso, percebemos e debatemos a importância de conscientizar os profissionais desta área sobre as leis vigentes da ergonomia, inclusive a RN 32, com o propósito de aprimoramento dos espaços de trabalho, para que disponham de qualidade de vida e melhor execução dos serviços.

Isso significa que a pesquisa em si pode contribuir notadamente com outros acadêmicos ou pesquisadores, como também com outros trabalhos relacionados a este tema, já que é tão significativa a conscientização e as mudanças a serem 
prestadas. Há ainda a possibilidade de reaplicar a pesquisa futuramente para uma percepção das mudanças ocorridas.

\section{REFERÊNCIAS}

CHANCHAI, W.; KETSOMPORN, P.; SAPPAKITCHANCHAI, P.; SIRIWONG, W.; ROBSON, M. G. et al. The Impact of an Ergonomics Intervention on Psychosocial Factors and Musculoskeletal Symptoms among Thai Hospital Orderlies. International journal of environmental research and public health, v. 13, n. 5, 2016. Disponível em: https://doi.org/10.3390/ijerph13050464.

DE MAGALHÃES, A. M. M.; DALL'AGNOL, C. M.; MARCK, P. B. Carga de trabalho da equipe de enfermagem e segurança do paciente-estudo com método misto na abordagem ecológica restaurativa. Revista Latino-Americana de Enfermagem, v. 21, n. spe, p. 146-154, 2013. ISSN 15188345. Disponível em: https://doi.org/10.1590/S0104-11692013000700019.

DUARTE, N. S.; MAURO, M. Y. C. Análise dos fatores de riscos ocupacionais do trabalho de enfermagem sob a ótica dos enfermeiros. Rev. bras. Saúde ocup, v. 35, n. 121, p. 157-167, 2010. ISSN 0303-7657. Disponível em: https://doi.org/10.1590/S0303-76572010000100017.

GALLAS, S. R.; FONTANA, R. T. Biossegurança e a enfermagem nos cuidados clínicos: contribuições para a saúde do trabalhador. Revista Brasileira de Enfermagem, v. 63, n. 5, p. 786-792, 2010. ISSN 0034-7167. Disponível em: https://doi.org/10.1590/S0034-71672010000500015.

GUIDO, L. de A. et al. Estresse, coping e estado de saúde entre enfermeiros hospitalares. Revista da Escola de Enfermagem da USP, v. 45, n. 6, p. 1434-1439, 2011. ISSN 0080-6234. Disponível em: https://doi.org/10.1590/S0080-62342011000600022.

HANSEN, B. B.; KIRKESKOV, L.; BEGTRUP, L. M.; BOESEN, M.; BLIDDAL, H.; CHRISTENSEN, R.; ANDREASEN, D. L.; KRISTENSEN, L. E.; FLACHS, E. M.; KRYGER, A. I. Early occupational intervention for people with low back pain in physically demanding jobs: a randomized clinical trial. PLoS Medidine, v. 16, n. 8, 2019. Disponível em: https://doi.org/10.1371/journal.pmed.1002898.

HOLMGREN, K. et al. Does early identification of work-related stress, combined with feedback at GP-consultation, prevent sick leave in the following 12 months? a randomized controlled trial in primary health care. BMC publichealth, v. 19, n. 1, 2019. Disponível em: https://doi.org/10.1186/s12889-019-7452-3.

LOPES, D. F. de M. et al. Ser trabalhador de enfermagem da Unidade de Centro de Material: uma abordagem fenomenológica. Revista da Escola de Enfermagem da USP, v. 41, n. 4, p. 675-682, 2007. ISSN 1980-220X. Disponível em: http://dx.doi.org/10.1590/S0080-62342007000400019.

MACHOVÁ, K.; SOUKOVÁ, M.; PROCHÁZKOVÁ, R.; VANÍCKOVÁ, Z.; MEZIAN, K. et al. Canine-Assisted Therapy Improves Well-Being in Nurses. International journal of environmental research and public health, v. 16, n. 19, 2019. Disponível em: https://doi.org/10.3390/ijerph16193670.

MARQUES, G. Q.; LIMA, M. A. D. da S. Organização tecnológica do trabalho em um pronto atendimento e a autonomia do trabalhador de enfermagem. Revista da Escola de Enfermagem da $U S P$, v. 42, n. 1, p. 41-47, 2008. ISSN 1980-220X. Disponível em: https://doi.org/10.1590/S008062342008000100006 .

MILOSAVLJEVIC, S.; ABBOTT, J. H. Effectiveness of a lumbopelvic monitor and feedback device to change postural behaviour: a protocol for the ELF cluster randomised controlled trial. BMJ open, v. 7, n. 1, 2017. Disponível em: https://doi.org/10.1136/bmjopen-2016-015568.

NEVES, H. C. C. et al. Segurança dos trabalhadores de enfermagem e fatores determinantes para adesão aos equipamentos de proteção individual. Rev Latino-Am. Enfermagem, v. 19, n. 2, p. 354361, 2011. ISSN 1518-8345. Disponível em: https://doi.org/10.1590/S010411692011000200018. 
NOBEN, C.; EVERS, S.; NIEUWENHUIJSEN, K.; KETELAAR, S.; GÄRTNER, F.; SLUITER, J.; SMIT, F. Protecting and promoting mental health of nurses in the hospital setting: is it cost-effective from an employer's perspective?. International journal of occupational medicine and environmental health, v. 28, n. 5, p. 891-900, 2015. Disponível em: https://doi.org/10.13075/ijomeh.1896.00465.

PINHEIRO, J.; ZEITOUNE, R. C. G. Hepatite B: conhecimento e medidas de biossegurança e a saúde do trabalhador de enfermagem. Escola Anna Nery Revista de Enfermagem, v. 12, n. 2, p. 258-264, 2008. ISSN 1414-8145. Disponível em: https://doi.org/10.1590/S1414-81452008000200009.

RASMUSSEN, C. D. N.; LINDBERG, N. K.; RAVN, M. H.; JORGENSEN, M. B.; SOGAARD, K.; HOLTERMANN, A. Processes, barriers and facilitators to implementation of a participatory ergonomics program among eldercare workers. Applied Ergonomics, v. 58, p. 491-499, 2017. Disponível em: https://doi.org/10.1016/j.apergo.2016.08.009.

SERRANHEIRA, F.; SOUSA-UVA, M.; SOUSA-UVA, A. Lombalgias e trabalho hospitalar em enfermeiro(a)s. Revista Brasileira de Medicina do Trabalho, v. 10, n. 2, p. 80-87, 2012. Disponível em: https://cdn.publisher.gn1.link/rbmt.org.br/pdf/v10n2a06.pdf.

SILVA, R. M. da et al. Trabalho noturno e a repercussão na saúde dos enfermeiros. Escola Anna Nery Revista de Enfermagem, v. 15, n. 2, p. 270-6, 2011. ISSN 1414-8145. Disponível em: https://doi.org/10.1590/S1414-81452011000200008.

SOLER-FONT, M. et al. Multifaceted intervention for the prevention and management of musculoskeletal pain in nursing staff: Results of a cluster randomized controlled trial. PloS One, v. 14, n. 11, e0225198, 2019. Disponível em: https://doi.org/10.1371/journal.pone.0225198.

TEIXEIRA, R. de C.; MANTOVANI, M. de F. Enfermeiros com doença crônica: as relações com o adoecimento, a prevenção e o processo de trabalho. Revista da Escola de Enfermagem da USP, v. 43, n. 2, p. 415-421, 2009. ISSN 1980-220X. Disponível em: https://doi.org/10.1590/S008062342009000200022 . 